\title{
Experimental Assessment of a Skyhook Semiactive Strategy for Seismic Vibration Control of a Steel Structure
}

\author{
Nicola Caterino $\mathbb{D},{ }^{1,2}$ Mariacristina Spizzuoco $\mathbb{D D}^{3}{ }^{3}$ \\ Antonio Occhiuzzi $\left(\mathbb{D},{ }^{1,2}\right.$ and Antonio Bonati ${ }^{2}$ \\ ${ }^{1}$ Department of Engineering, University of Naples "Parthenope", Naples, Italy \\ ${ }^{2}$ Construction Technologies Institute (ITC), National Research Council (CNR), San Giuliano Milanese, Milan, Italy \\ ${ }^{3}$ Department of Structures for Engineering and Architecture, University of Naples Federico II, Naples, Italy
}

Correspondence should be addressed to Nicola Caterino; nicola.caterino@uniparthenope.it

Received 25 August 2017; Accepted 28 January 2018; Published 22 February 2018

Academic Editor: Giada Gasparini

Copyright (C) 2018 Nicola Caterino et al. This is an open access article distributed under the Creative Commons Attribution License, which permits unrestricted use, distribution, and reproduction in any medium, provided the original work is properly cited.

Sky-hook damping is one of the most promising techniques for feedback control of structural vibrations. It is based on the idea of connecting the structure to an ideal fixed point of the space through passive dissipative devices. Herein the benefit of semiactive (SA) sky-hook (SH) damping is investigated for seismic protection of a two-storey steel frame via shaking table tests. This kind of SA control is achieved implementing a continuous monitoring of selected structural response parameters and using variable dampers. The damping properties of the latter are changed in real-time so as to make the force provided by the damper match the desired $\mathrm{SH}$ damping force as closely as possible. To this aim, two prototype magnetorheological dampers have been installed at the first level of the frame and remotely driven by a SH controller. The effectiveness of the control strategy is measured as response to reduction in terms of floor accelerations and interstory drift in respect to the uncontrolled configuration. Two different calibrations of the $\mathrm{SH}$ controller have been tested. The experimental results are deeply discussed in order to identify the optimal one and understand the motivations of its better performance.

\section{Introduction}

Semiactive (SA) structural control systems rely on smart devices able to provide a rapid variation of their stiffness and/or damping properties. Although the probably first implementation of a SA structural control system is based on variable stiffness devices [1], today most of the research efforts are aimed at the adoption of variable damping schemes. The latter idea was first introduced in the early 1970s by Crosby and Karnopp [2], who showed the possibility of exploiting a variable-constant viscous damper in the context of automotive industry. The original work of Crosby and Karnopp envisioned a SA suspension driven by a two-state switching policy that makes the viscous damper behave pretty much like a sky-hook device. One of the advantages of such idea is the corresponding model-free control algorithm, whose implementation does not require a previous knowledge of the system parameters and/or of the external excitation [3].
Although these control algorithms are widely described in the scientific literature, their effectiveness is almost always shown by numerical applications. Notable exceptions are cited in the following. Li and $\mathrm{Xu}$ [4] performed shaking table tests on a three-storey one-bay frame model, controlled by a double-ended shear mode combined with valve mode MR fluid device placed between the ground and the first floor. The validity of the SA control system was verified by implementing three different control algorithms: the instantaneous optimal control algorithm, the classical linear optimal control algorithm, and the linear-quadratic Gaussian control algorithm. Lee et al. [5] adopted a full-scale five-storey testing structure to make an experimental comparison of different SA algorithms (Lyapunov algorithm, neurocontrol logic, and maximum energy dissipation algorithm) to control the behavior of the MR damper-based system, under the effect of four historical earthquakes and one artificial seismic input. Basili et al. [6] carried out shaking table tests to verify the effectiveness of a SA MR damper system in reducing seismic 


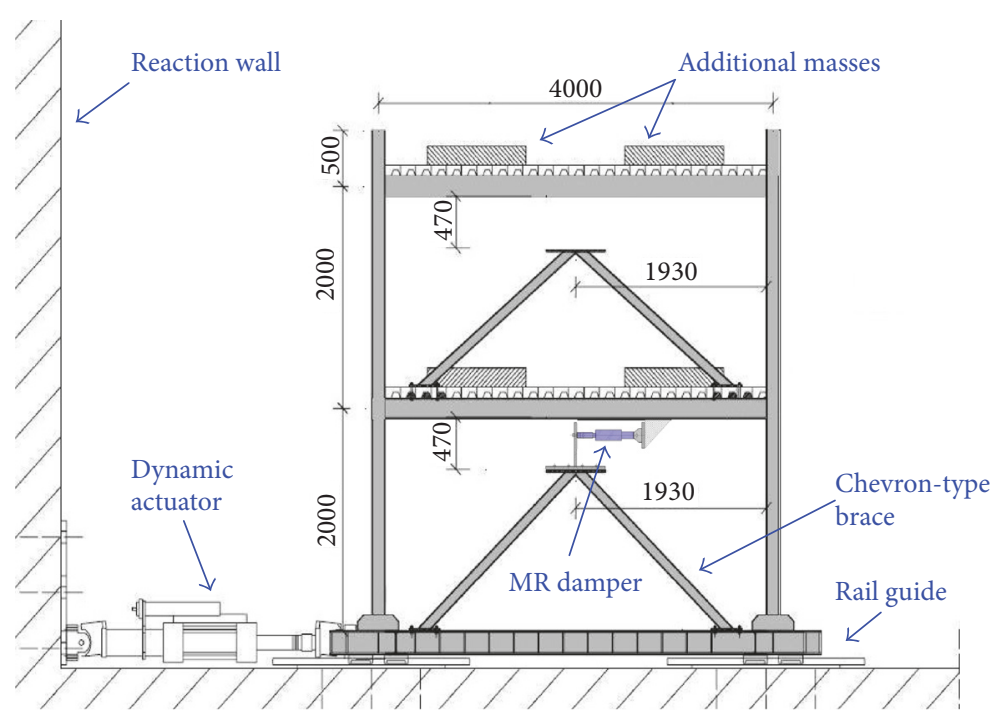

FIGURE 1: Experimental setup (dimensions in $\mathrm{mm}$ ).

vibrations of adjacent structures. The physical model is represented by two 1:5 scaled steel structures connected at the second level by a commercial MR damper driven by an on-off control algorithm derived from the Lyapunov stability theory. Cha et al. [7] presented a comparison among response reduction performances of three SA control algorithms for use with MR dampers: the clipped-optimal controller, the decentralized output feedback polynomial controller, and the simple passive controller. Real-time hybrid tests under four different earthquakes were carried out by considering an analytical building model and two physical models of largescale MR dampers stroked by hydraulic actuators.

A large scale steel frame equipped with two semiactive (SA) bracing systems (Figure 1) has been the object of a wide experimental campaign performed by the authors [8] at the Structural Engineering Laboratory of the University of Basilicata in Potenza (Italy) within the so-called JETPACS (Joint experimental testing on Passive and semi active control systems) research program performed in the framework of the ReLUIS Italian research project [9]. In the previous work [8], the authors presented a general overview of the experimental activity, from the selection of the seismic input up to the preliminary assessment of the operation of four different algorithms selected from the literature: "energy" (that aims at maximizing the energy extracted by the damper from the structure, based on [10], following a bang-bang approach), "modulated homogeneous friction" (that modulates the current intensity into the damper according to the interstory drift demand [11]), "acceleration reduction" (that derives from the study in [12] about the reduction of vibrations for industrial machines), and "sky-hook" (that originates from [2]).

Herein the study focuses on the latter algorithm, in which the preliminary comparison between algorithms has shown to be among the most suitable for the specific application. First the state of the art about this control strategy is presented; then the design phases that led to the practical implementation to the case study structure are shown. Finally, the effectiveness of the controller in reducing the dynamic structural response is deeply assessed and discussed, looking at the demand to both structural and nonstructural components (interstory drift), as well as contents (floor acceleration time histories and spectra), finally analyzing if and how the controller achieves the performance goals its philosophy is based on. The experimental performance of two different configurations of the $\mathrm{SH}$ controller is compared. The optimal one is identified, also discussing the reasons that lead to better performance.

The said controller is inspired by the "sky-hook" theory, originally formulated for vehicle suspension applications. Sky-hook (SH) damping is a form of feedback vibration control. The benefit of SH damping is that it damps resonant peaks in the transfer function of the structure without increasing high frequency transmissibility. The idea of a $\mathrm{SH}$ damper, that is a dissipative device virtually constrained to the fixed space, was pioneered by Crosby and Karnopp [2]. A SH SA control can be achieved using variable dampers whose damping properties are changed in real-time so as to make the force provided by the damper match the desired $\mathrm{SH}$ damping force as closely as possible. This is what has been done herein, installing two magnetorheological (MR) dampers at the first floor of the structure, remotely commanded by a specific electronic equipment, and according to a control algorithm purposely written. The devices are prototypes designed and manufactured by the German company Maurer Söhne.

The above controller requires that the structural system has to be continuously monitored; however, only few and local measurements of the structural response are needed and the knowledge of the dynamic characteristics of the structure not necessarily must be known. The issues related to real-time monitoring are discussed herein with reference to the case study, also allowing drawing conclusions that are generally valid.

In the following, first the experimental set-up is described (structural components, sensors for measurements, 

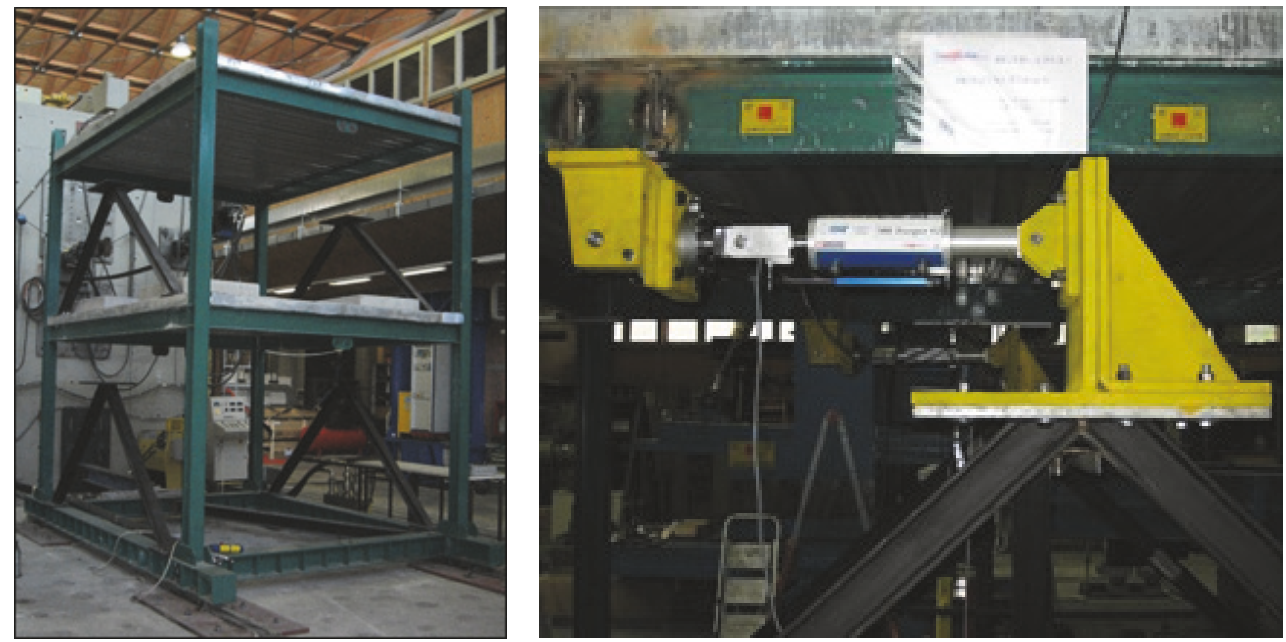

Figure 2: The experimental mock-up structure.

electronic equipment for monitoring, and control). Then the $\mathrm{SH}$ controller is presented, as it has been designed for such particular application. With reference to a natural earthquake record, whose action is simulated through a shaking table facility, the response of the uncontrolled and of the SA controlled structure is compared in terms of displacements and accelerations, so as to evaluate the effectiveness of the $\mathrm{SH}$ controller in reducing the structural response of the frame.

\section{Experimental Setup and Activity}

The steel structure is a 2-storey one-bay steel frame with composite steel-reinforced concrete slabs (Figure 2). The mock-up structure is of plan size $3 \mathrm{~m} \times 4 \mathrm{~m}$ with a total height of about $4.5 \mathrm{~m}$ : four columns with HEB140 profile are placed at the corners with their flanges oriented parallel to the transverse $(Y)$ axis. Four lateral beams IPE180, welded to the columns, comprise the first and second floors, while four lateral beams of HEB220 comprise the ground floor. Additionally, a horizontal bracing of HEA160 is provided on the horizontal plane at the ground floor. All structural elements are made of Fe360 steel. A concrete slab supported by coffer steel sections A55/P600 with $0.8 \mathrm{~mm}$ thickness is provided at the first and second floors. In order to make longer the vibration periods of the frame, a modified symmetrical configuration has been obtained by adding on each floor four concrete blocks with different masses of approximately $340 \mathrm{~kg}$ each (Figure 1). The frame is supported on special sliding $1 \mathrm{D}$ guides positioned under the base beams, close to the column location, which allow the frame to move in the longitudinal $(X)$ direction only.

To allow the mounting of the semiactive devices, two chevron-type bracings made of steel profile HEA100 are mounted along the long edge (longitudinal) direction of the frame between ground and first floor and are connected to the lower floor beams at a certain distance from the columns.

The semiactive MR dampers have been provided by Maurer Söhne (Munich, Germany) and experimentally tested at the Laboratory of the Department of Structural Engineering

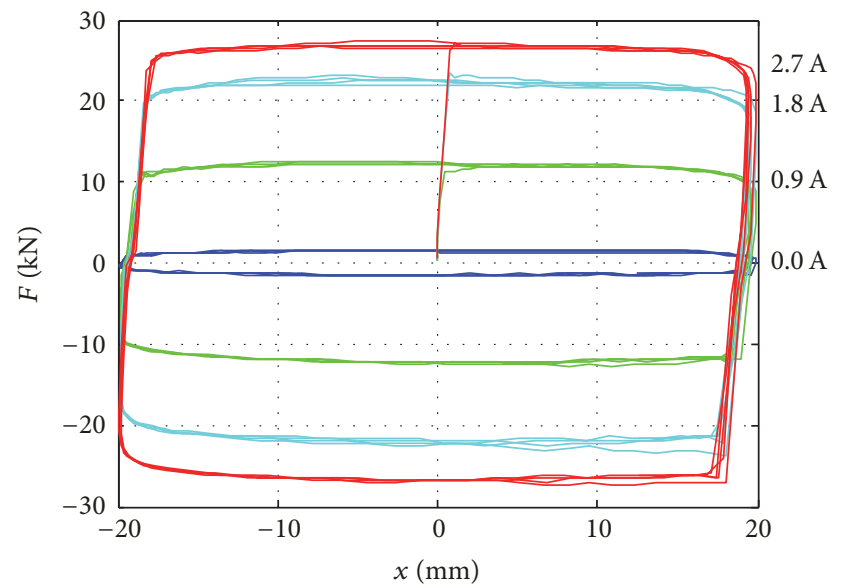

FIGURE 3: Cyclic force-displacement behaviour of the adopted prototype MR dampers [13].

of the University of Napoli Federico II, in order to evaluate the characteristics of their operations $[13,15]$. They look pretty much like conventional fluid viscous damper, with the exception of some extra wiring needed to feed the coils inside the body. The absence of moving parts like electrically controlled valves or mechanisms make them very reliable with respect to other semiactive devices. Each prototype MR device has overall dimensions $675 \mathrm{~mm}$ (length) $\times 100 \mathrm{~mm}$ (external diameter) and a mass, without connections, approximately equal to $16 \mathrm{~kg}$; it can develop a maximum damping force of $30 \mathrm{kN}$ along its longitudinal axis and the piston stroke is equal to $\pm 25 \mathrm{~mm}$. The magnetic field produced in the device is generated by a magnetic circuit, and the current in the circuit, provided by a power supply commanded by a voltage input signal, is in the range $i=0 \div 3 \mathrm{~A}$. Figure 3 shows the results of four "passive" tests performed during the experimental campaign described in $[13,15]$, carried out at the same displacement frequency $(1.5 \mathrm{~Hz})$ and amplitude $(20 \mathrm{~mm})$, supplying four different currents (0 A, 0.9 A, 1.8 A, 


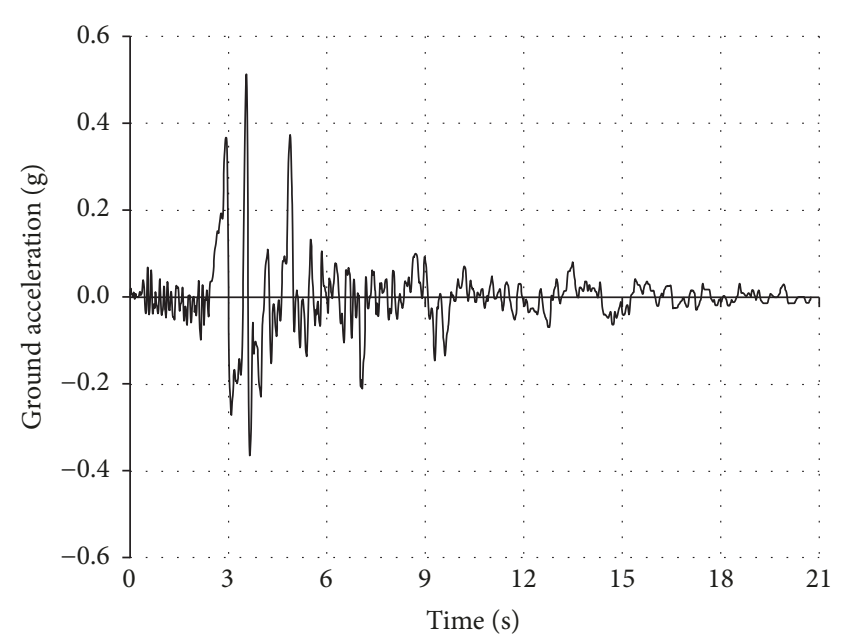

(a)

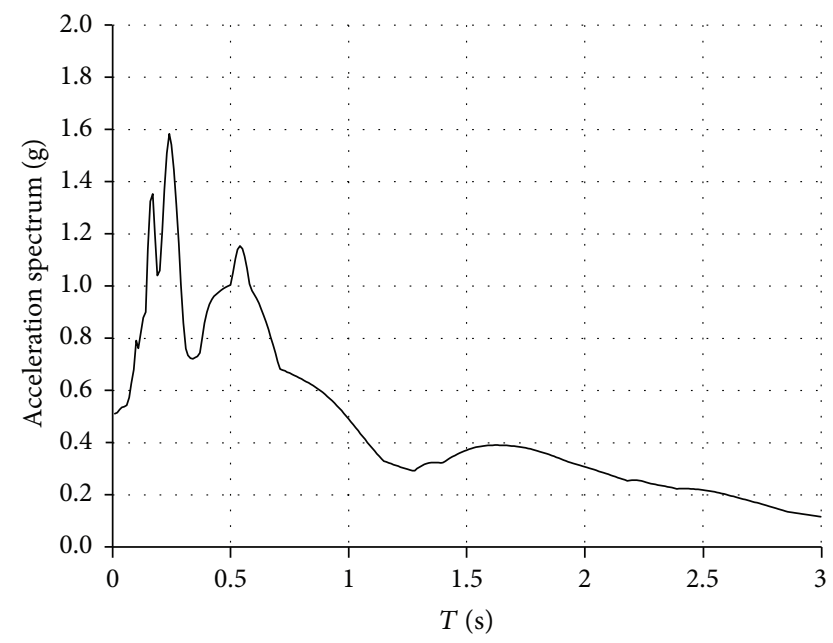

(b)

FIGURE 4: Erzincan earthquake: accelerogram (a) and 5\% damped elastic acceleration spectra (b).

and $2.7 \mathrm{~A}$ ). It shows how much the response behavior is variable according to the feeding current.

The registration of the Erzincan earthquake (code of the seismic record 000535y, direction N74E, magnitude 7.3, fault distance $8 \mathrm{~km}$, date 13/03/1992, station Erzincan-Mudurlugu, Turkey) has been adopted for the experimental analyses (Figure 4).

The time scale of the accelerogram has been reduced by a factor $\sqrt{ } 1.5$ according to the scale of the model. Seismic input has been applied at increasing amplitudes for subsequent tests, up to the achievement of a safety limit value for the interstory drift (about $10 \mathrm{~mm}$ ) or for the absolute floor acceleration $(2 \mathrm{~g})$. The said record $000535 \mathrm{y}$ has demonstrated to be particularly damaging for the structure; therefore, it has been applied scaled at a maximum $38 \%$ of its real intensity. In the following, this is the seismic load all the analyses and results will be referred to.

A total of 22 transducers were adopted to monitor the response of the structure during the SA tests $[9,16]$, placed as represented in Figure 5. The horizontal displacements of each floor were measured through four digital transducers (D1 to D4) fixed to an external steel reference frame. The floor accelerations were recorded through four $X$-direction horizontal and four $Y$-direction horizontal (A5 to A12). The table-model base accelerations were recorded through two $X$ direction horizontal and two $Y$-direction accelerometers (A1 to A4), whereas the displacement by one digital transducer (D0) was fixed to the external steel reference frame. An additional accelerometer was adopted to measure acceleration of the actuator (A0) along its longitudinal axis. The remaining channels were used to measure the force of the dissipating devices, by means of piezoresistive load cells (F1 and F2) mounted at the end of each device and relative displacement, by means of four displacement transducers (D5 and D6). Table 1 gives detailed information about model and characteristics of the adopted sensors.

The special electronic equipment adopted to acquire the online measurement signals coming from the monitoring
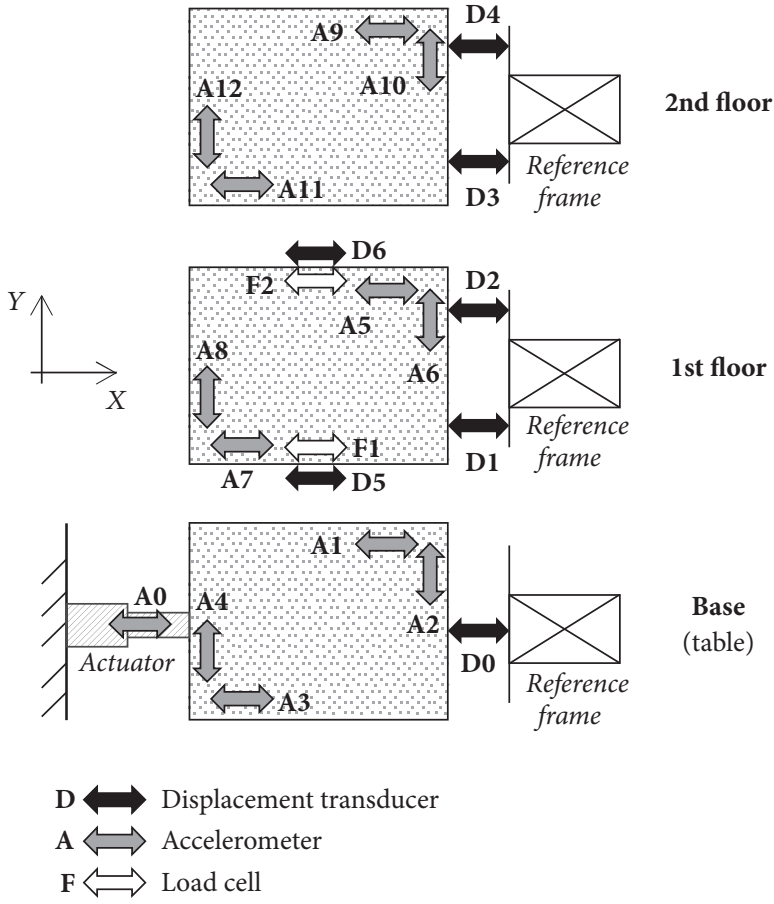

FIGURE 5: Plan view of base, 1st floor, and 2nd floor: position of sensors. D5 and D6 measured displacement demand in MR dampers. F1 and F2 measured the reaction's force of these devices.

activity and to drive MR dampers is depicted in Figure 6. The promptness of the whole system in acquiring and processing data and in commanding the dampers plays a crucial role for the effectiveness in controlling vibrations. Recent experimental studies [4, 17] highlighted the crucial role of the power supplies technology among the factors influencing the fast response of the SA control chain. Those referred to as "power source-power sink" allow to choose indifferently one of the two alternative schemes of control, 
TABLE 1: Sensors adopted to monitor the structural response during the tests.

\begin{tabular}{lrc}
\hline Quantity & Transducer & Label in Figure 5 \\
\hline 5 & Temposonic digital transducers, $\pm 250 \mathrm{~mm}, 2 \mu \mathrm{m}$ of resolution & D0 to D4 \\
5 & Columbia servo-accelerometers, model SA-107LN, $\pm 1 \mathrm{~g}$ & A0 to A4 \\
2 & Penny \& Giles LP displacement transducers, type HLP190/SA, $\pm 50 \mathrm{~mm}$ & D5 to D6 \\
8 & FGP servoaccelerometers, model FA101-A2, $\pm 2 \mathrm{~g}$ & A5 to A12 \\
2 & AEP load cell, model TC4, $\pm 50 \mathrm{kN}$ & F1 to F2 \\
\hline
\end{tabular}

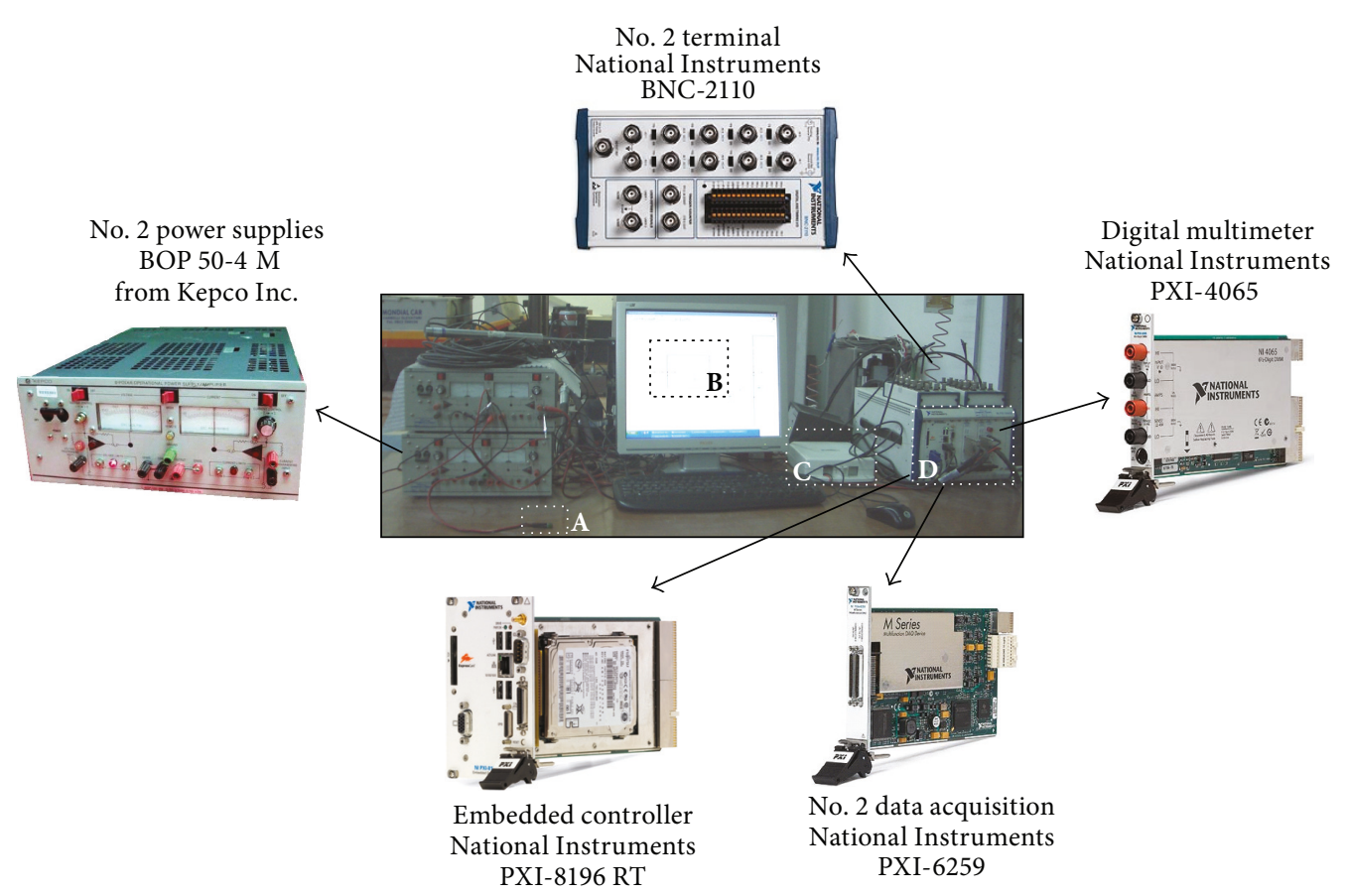

FIGURE 6: Electronic equipment for acquisition and control during the JET-PACS experimental tests.

that is, voltage-driven or control-driven. The voltage-driven scheme is demonstrated to lead to response delays more than an order of magnitude larger than those achievable with a current-driven approach. In the last case, the overall response time is comfortably bounded to $8 \sim 10 \mathrm{~ms}$, so leading to negligible effects on the effectiveness of the control strategy.

In this case, operational power suppliers BOP 50-4 M (Kepco Inc.) were adopted, with an output power of $200 \mathrm{~W}$, a maximum input power of $450 \mathrm{~W}$, and an output range of $\pm 50 \mathrm{~V}$. Moreover, the tools they adopted to acquire signals, also usable for real applications, were a National Instruments (NI) PXI 6259 data acquisition board with 16 inputs and 4 outputs $( \pm 10 \mathrm{~V}$ voltage signals, 16 bit resolution, and $2800 \mathrm{kHz}$ maximum sampling rate), the NI Labview Professional Development System, release 8.5, digital multimeters to measure the intensity of current in the circuit of the MR dampers (Figure 6).

\section{Design of a Semiactive Sky-Hook Damper}

The control algorithm tested aimed to make the SA damper behave like a SH damper, that is, a damper constrained to the fixed space $[2,14,18]$. A conventional damper (Figure 7(a);
Figure 8, black lines) leads to resonance curves where for increasing values of damping the resonant response reduces, but this decrease is obtained only at the cost of an increased response for high frequencies. SH dampers (Figure 7(b); Figure 8, gray lines) guarantee an overall response reduction at all frequencies and tend to avoid resonance. Figure 8 is a rearrangement of what Karnopp et al. showed in [14]. A conventional and a SH damping scheme are compared showing the transmissibility of displacement from the base $\left(x_{0}\right)$ to the vibrating mass ( $x$, absolute) subjected to sinusoidal inputs with frequency $\omega$. The natural frequency of the system is referred to as $\omega_{n}$, while the damping ratio is $\xi$. For low input frequencies $\left(\omega<\omega_{n}\right)$, small relative displacements occur for both systems. For values of $\omega$ close to $\omega_{n}$ the role of the damping becomes more evident and controls the resonance of the system. In this case, small values of damping ratio lead to high response of both dynamic systems. However, for higher values of $\xi$, it is worth noting that the resonance effect is highly mitigated, and the high frequency response decreases. A conventional damping scheme leads instead to resonance curves where increasing values of damping ratio still make the resonant response reduce, but this decrease is obtained only at the cost of an increased response against high frequencies. 


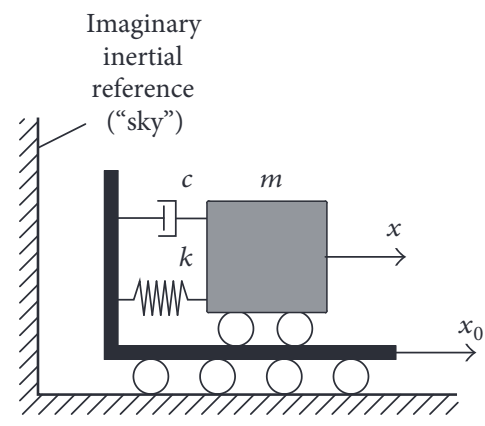

(a)

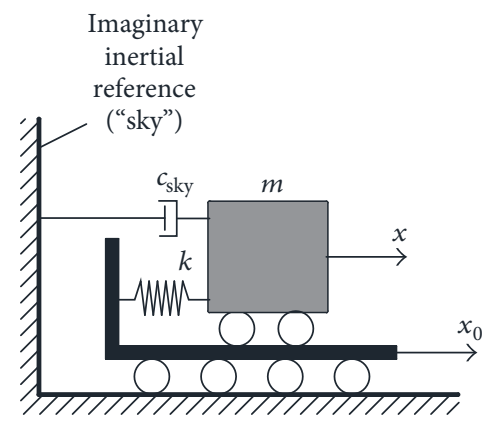

(b)

Figure 7: Conventional (a) and ideal sky-hook (b) damping schemes for a single degree of freedom system.

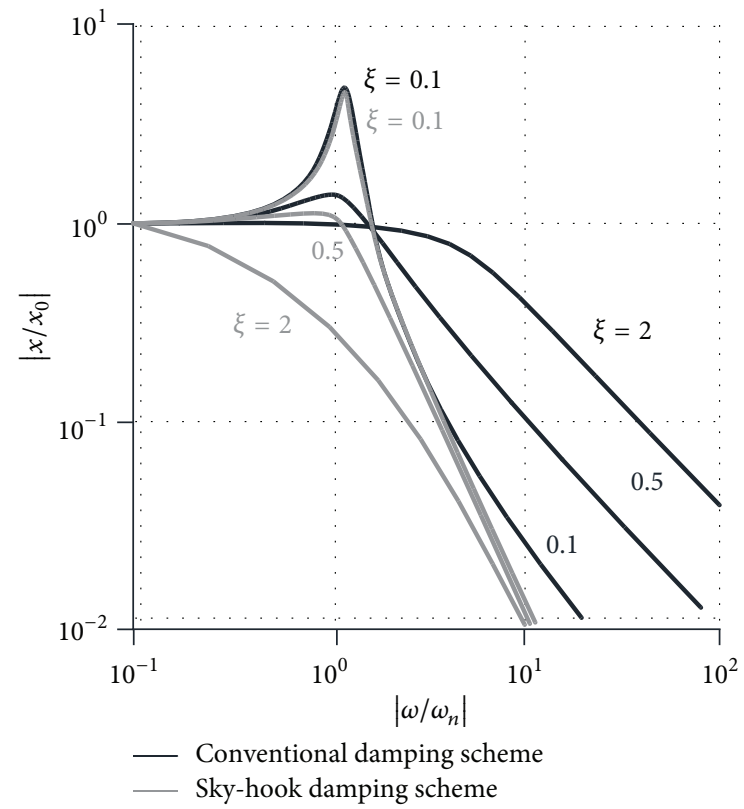

FIGURE 8: Conventional (black) and ideal sky-hook (grey) damping schemes: comparison of vibration transmissibility at three levels of damping ratio (rearranged from [14]).

The force exerted by the conventional viscous damper in Figure $7(\mathrm{a})$ is

$$
F_{v}(t)=c \cdot\left[\dot{x}(t)-\dot{x}_{0}(t)\right],
$$

whereas for a SH viscous damper (Figure 7(b)) it would be

$$
F_{\text {sky }}(t)=c_{\text {sky }} \dot{x}(t),
$$

where $x$ and $x_{0}$ are, respectively, the absolute displacement of the mass and that of the base (ground).

Ideally, a conventional damper may behave like a $\mathrm{SH}$ device if its constant $c$ could vary in real-time making, instant by instant, $F_{v}(t)$ equal to $F_{\text {sky }}(t)$. This could be actually realized by means of active control devices. Semiactive dampers cannot do exactly this; however, it can effectively mimic the behavior of a SH device if the SA control algorithm is based on a logic similar to that in (3), where $i(t)$ is the instantaneous

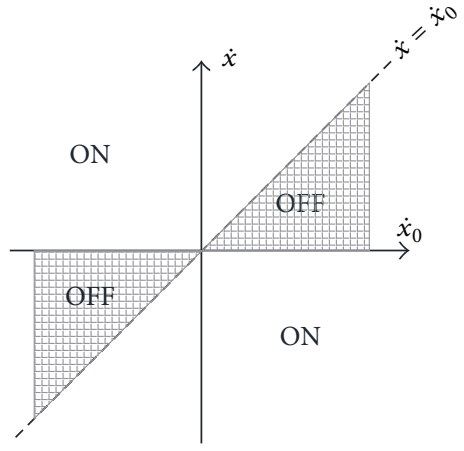

FIGURE 9: States of the MR dampers according to the velocity of the frame and of the ground, following the sky-hook control algorithm.

intensity of current given to the MR dampers. The same logic is also graphically depicted in Figure 9. In the instants of time when $F_{v}(t)$ have the same sign of the ideal SH force $F_{\text {sky }}(t)$, the SA damper is taken in the ON state (intensity of current set to the maximum value $\left.i_{\min }\right)$. In the other cases, it is "turned" OFF (intensity of current set to the minimum value $i_{\min }$ ) aiming to invert the undesired trend. This is because the damping constant cannot be set to a negative value. For the experimental study herein discussed, $i_{\min }$ has been set equal to $0 \mathrm{~A}$. Two different configurations of the $\mathrm{SH}$ controller have been tested through the shaking table facility, once setting $i_{\max }$ equal to $1 \mathrm{~A}$ and once to $\mathrm{A} 2$. As the reader can derive from Figure 3, the mechanical response of the MR dampers when fed with these two levels of current intensity is strongly different. Moreover, the current of $2 \mathrm{~A}$ almost leads to saturation of the magnetic field, as can be deduced again from Figure 3 where it can be observed that the response for current higher than $2 \mathrm{~A}$ is stronger, but not so much. Therefore, cases $1 \mathrm{~A}$ and $2 \mathrm{~A}$ can be considered representative of two opposite ways of calibrating the dampers.

$$
\begin{array}{ll}
\text { if } \dot{x}\left(\dot{x}-\dot{x}_{0}\right) \leq 0 & \text { then } i(t)=i_{\min }(\mathrm{OFF}) \\
\text { if } \dot{x}\left(\dot{x}-\dot{x}_{0}\right)>0 & \text { then } i(t)=i_{\max }(\mathrm{ON}) .
\end{array}
$$

This controller has been adapted to the JETPACS steel structure as schematically represented in Figure 10 and preliminarily discussed in [19]. In more detail, on the left 


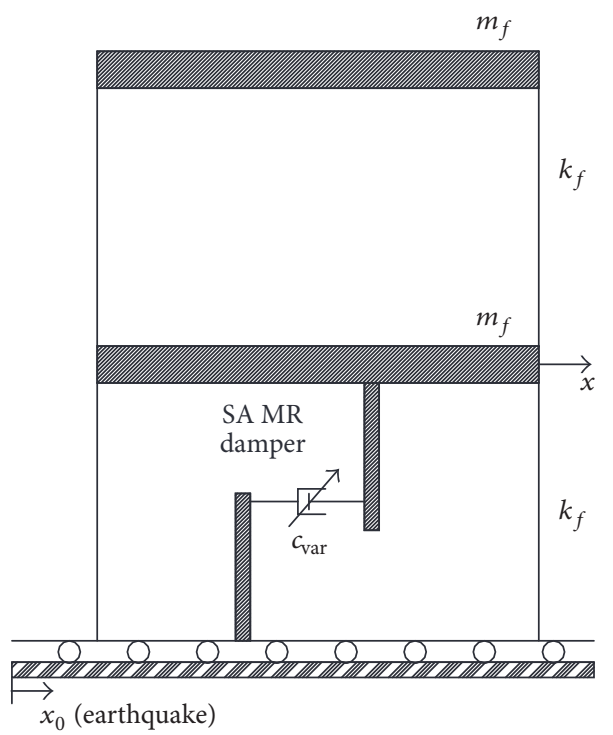

(a)

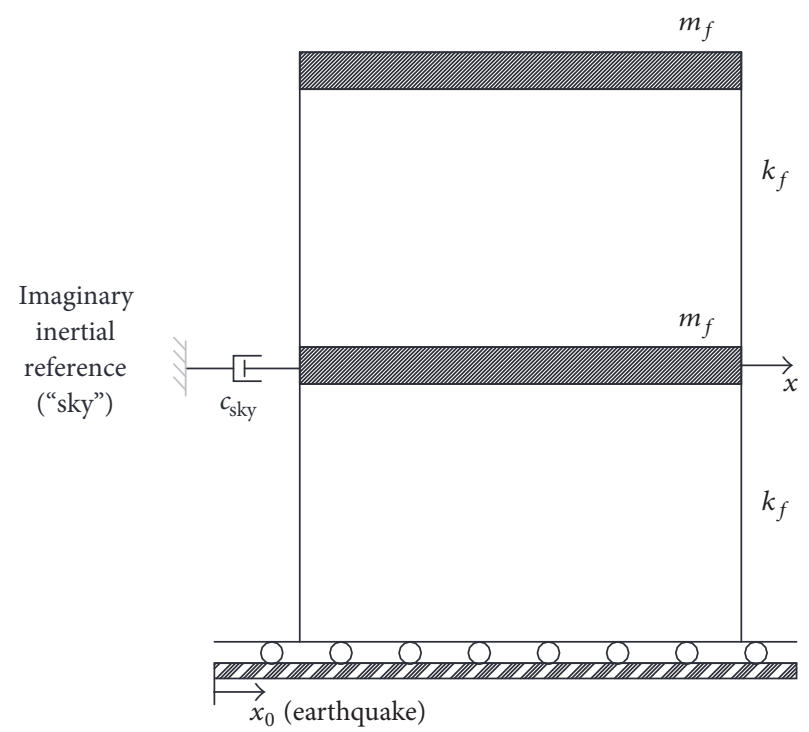

(b)

Figure 10: Sky-hook based semiactive control as designed for the case study structure (a). Sky-hook passive damping scheme taken as a reference to be emulated.

the meaning of $x$ (1st floor absolute displacement) and $x_{0}$ (movement of the ground, i.e., of the shaking table) is described. It is worth noting that the idea of this study was that of controlling the vibrations of such multi-degree of freedom structure adding SA damping only at the first level. On the right, the passive structural scheme is taken as a reference to be emulated through SA control.

\section{Experimental Results and Discussion}

The main results of the experimental campaign have been reported and discussed in this section. The acronyms SH1A and $\mathrm{SH} 2 \mathrm{~A}$ are used to refer to the two tests done with SH SA control set with $i_{\max }$ equal to $1 \mathrm{~A}$ and $2 \mathrm{~A}$, respectively. Figures 11(b) and 11(d) show the command voltage given to the MR dampers for tests SH1A and SH2A, respectively. It is worth noting that a $2 \mathrm{~s}$ long time window has been focused, in the most significant part of the motion, on a better readability of the charts. No evident difference is detected between the trends of the two graphs, except for the command voltage value corresponding to the $\mathrm{ON}$ state of the devices (about $2.5 \mathrm{~V}$ for SH1A, $5.0 \mathrm{~V}$ for SH2A). The SA control force exerted by the MR dampers during the two tests is shown in Figure $11(\mathrm{c})$. Peak values have been detected to be $10 \mathrm{kN}$ and $18 \mathrm{kN}$ for the two above SA tests, respectively.

The performance of the SA SH control strategy is evaluated comparing the response of the uncontrolled and controlled structure in terms of interstory drift demand, floor acceleration, and floor response spectra (FRS). The latter, as known, is strongly related to nonstructural components and contents demand [20].

Figure 12 summarizes the results in terms of lateral displacement demand. It allows clearly highlighting the significant reduction of demand the proposed control strategy in the SH1A case led to. Actually in this case the maximum 1st interstory drift resulted in being $5.1 \mathrm{~mm}$ for the uncontrolled structure and $2.7 \mathrm{~mm}$ for the controlled case. The maximum 2nd interstory drift passed from $6.9 \mathrm{~mm}$ to $4.7 \mathrm{~mm}$. Therefore a $30-45 \%$ of reduction in terms of displacements has been achieved. The SH2A test did not lead to the same good results. The peak value of displacement demand at the 1st level is reduced less than in the SH1A case, while at the 2nd level it results in being even greater $(8.3 \mathrm{~mm})$ than the value $(6.9 \mathrm{~mm})$ registered for the uncontrolled configuration.

Figure 13 shows floor acceleration time histories and spectra for the uncontrolled and the controlled structure, both for the SH1A and SH2A tests. Also in this case, the test SH1A led to better results compared to SH2A, given that the demand resulted in being strongly reduced for both levels of the structure. Calibration of the SA control with 2A (test $\mathrm{SH} 2 \mathrm{~A}$ ) even led to a worsening of the response for the first floor (peak acceleration $0.67 \mathrm{~g}$ in the uncontrolled case, $0.97 \mathrm{~g}$ in the SH2A case), at the same time not significantly reducing the large acceleration demand at the roof level. To the contrary, the SH1A test led to a strong mitigation of floors' acceleration demand, with percentage reduction in the range $30-50 \%$.

As known, the floor acceleration is one of the more effective parameters to measure seismic demand to nonstructural components and contents. Figures 13(e) and 13(f) show the 1st and 2nd floor response spectra, respectively. It is worth noting that both SA tests led to a high reduction of spectral accelerations in the low frequency range. However, for higher frequencies (lower periods) the trend is different. The SH1A test leads to results similar to those of the naked structure, even reducing the peak value, which occur for a period of about $0.08 \mathrm{~s}$. To the contrary, the $\mathrm{SH} 2 \mathrm{~A}$ test resulted in amplifying acceleration demand for low period $(<0.1 \mathrm{~s})$ components, in some cases even leading to spectral ordinates that are three times those of the uncontrolled structure. Also 


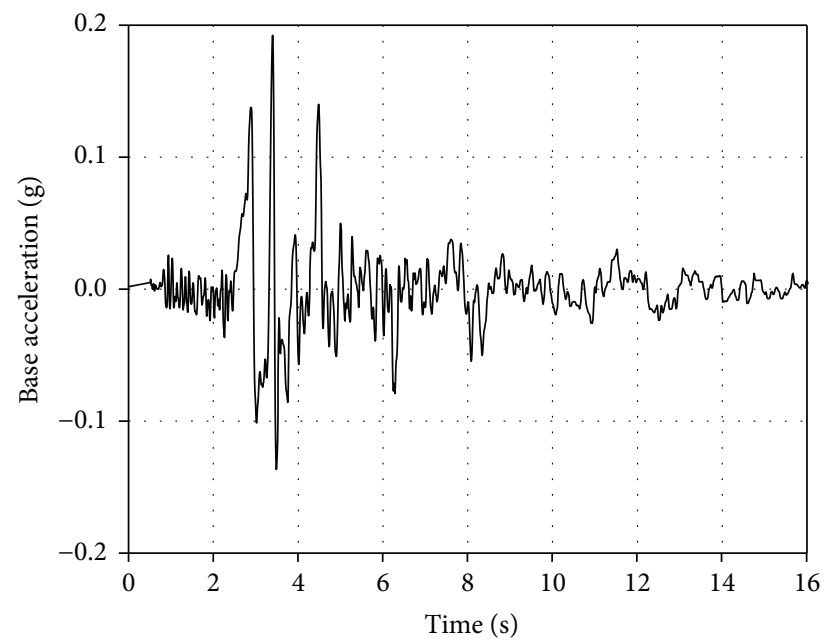

(a)

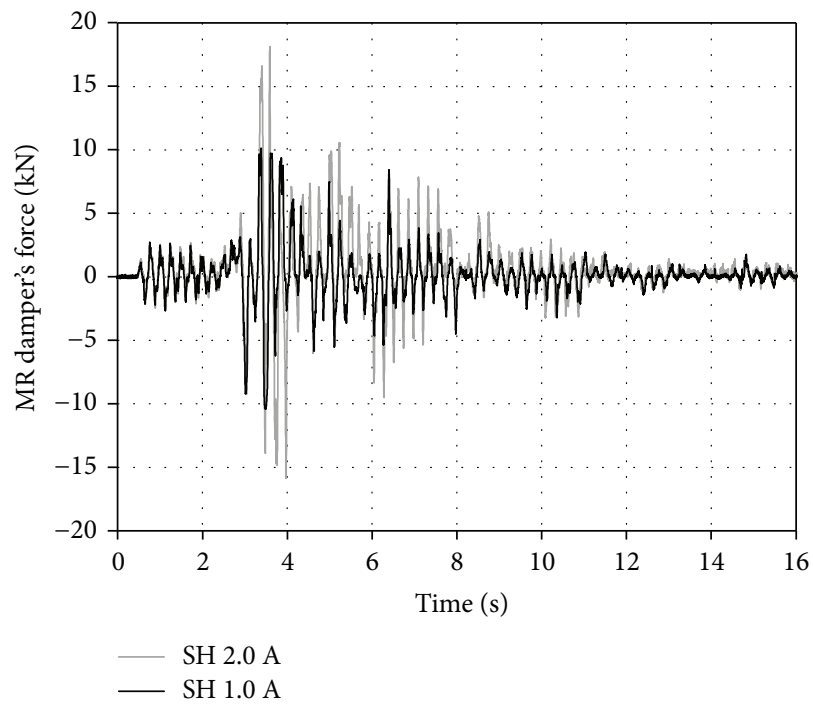

(c)

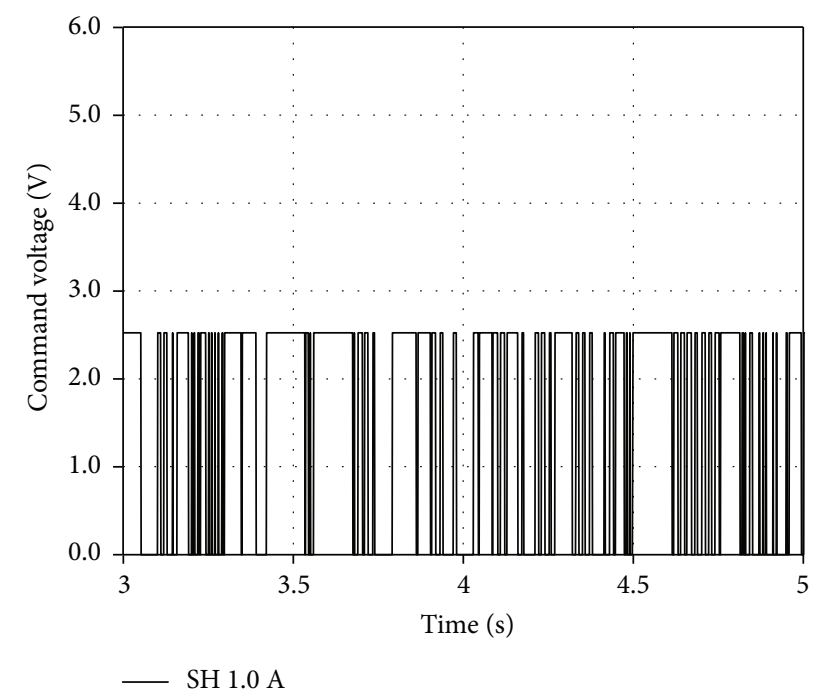

(b)

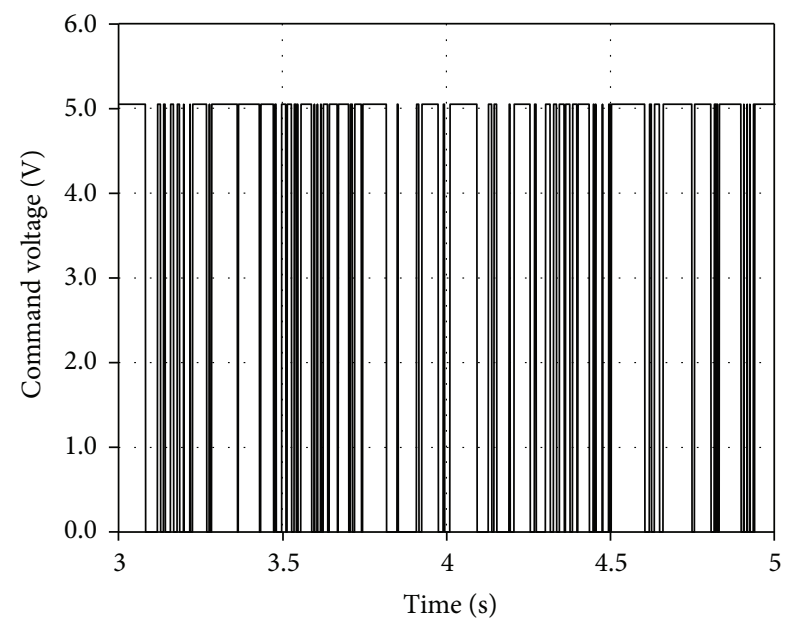

- SH $2.0 \mathrm{~A}$

FIGURE 11: SA tests: registration of base acceleration (a), command voltage (b, d), and damper's reacting force (c).

peak value at $0.08 \mathrm{~s}$ results in being amplified when the structure is SA controlled using $i_{\max }=2 \mathrm{~A}$.

To further compare the three cases (uncontrolled, SH1A, and $\mathrm{SH} 2 \mathrm{~A}$ ) in terms of demand to nonstructural components, four special periods of vibration have been selected and focused on. The results are summarized in Table 2. Selected periods are referred to generic components that could be installed to one of the two floors. In more detail,

(i) case (a) refers to a hypothetical component firmly fixed (period $T=0$ ) to the slab of the 1st or 2 nd floor; it is worth noting that, in such case, the spectral accelerations are equal to the PFA (peak floor accelerations) highlighted in Figures 13(a)-13(d);

(ii) case (b) is an ideal hollow clay partition wall having dimensions $2.5 \times 2 \times 0.3 \mathrm{~m}$ and weight per unit volume $8 \mathrm{kN} / \mathrm{m}^{3}$; according to the Italian building code [21], the vibration period of such component is equal to $0.02 \mathrm{~s}$;

(iii) case (c) is that of a component whose fundamental period is equal to the first resonance period of the floor where it is installed ( $0.29 \mathrm{~s}$ for the naked structure, $0.24 \mathrm{~s}$ for the SA controlled cases);

(iv) case (d) is that of a component whose fundamental period equal to the second resonance period of the floor where it is installed $(0.09 \mathrm{~s}$ for the naked structure, $0.08 \mathrm{~s}$ for the SA controlled cases).

Numerical values in Table 2 allow underlining once again that the $\mathrm{SH}$ controller calibrated with $i_{\max }=1 \mathrm{~A}$ results in being more effective in reducing seismic demand to nonstructural elements. When it is calibrated with $i_{\max }=2 \mathrm{~A}$, the dynamic response is sometimes even worse than the uncontrolled case, especially at the first floor. 


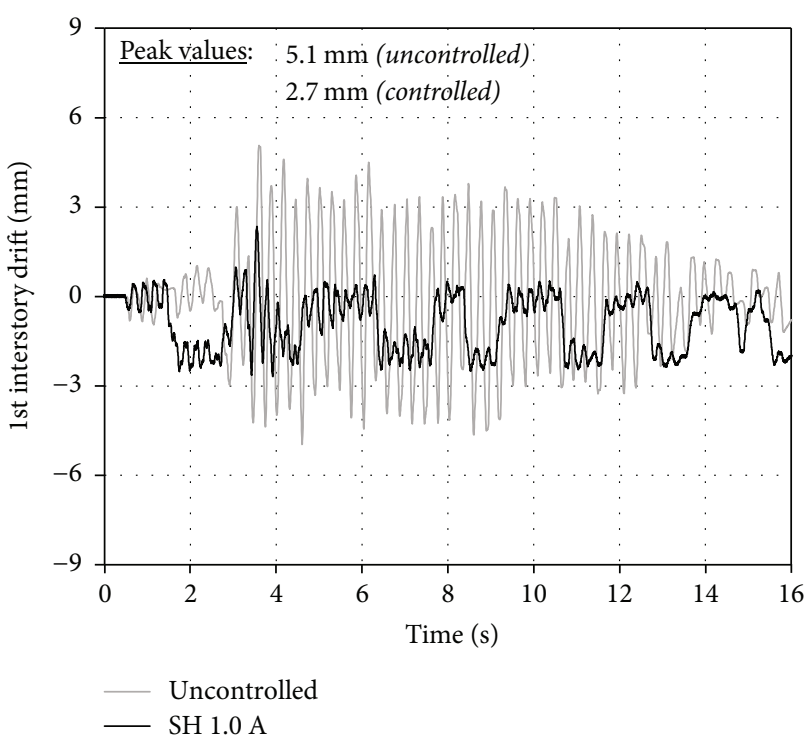

(a)

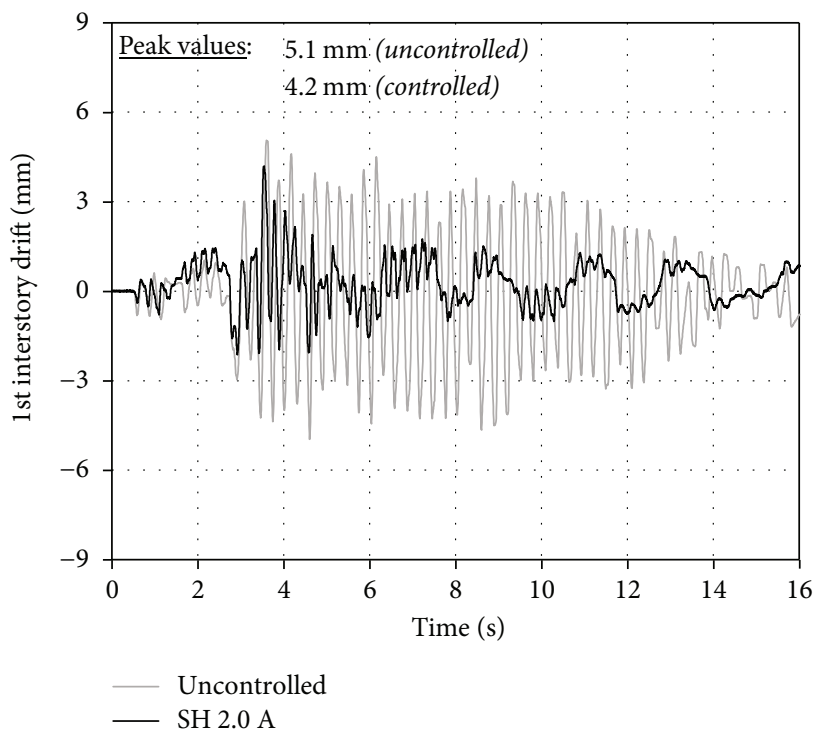

(c)

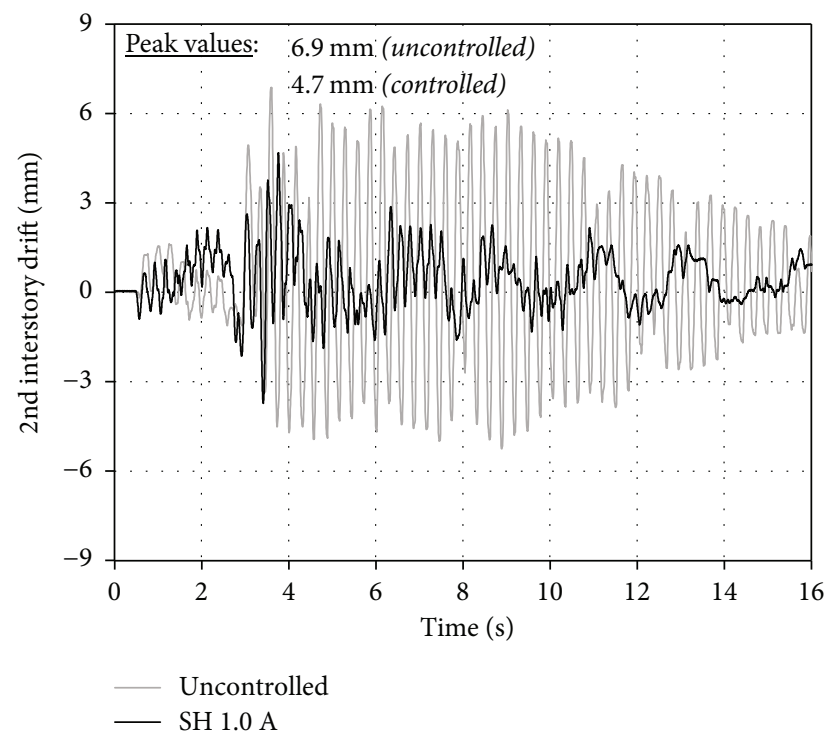

(b)

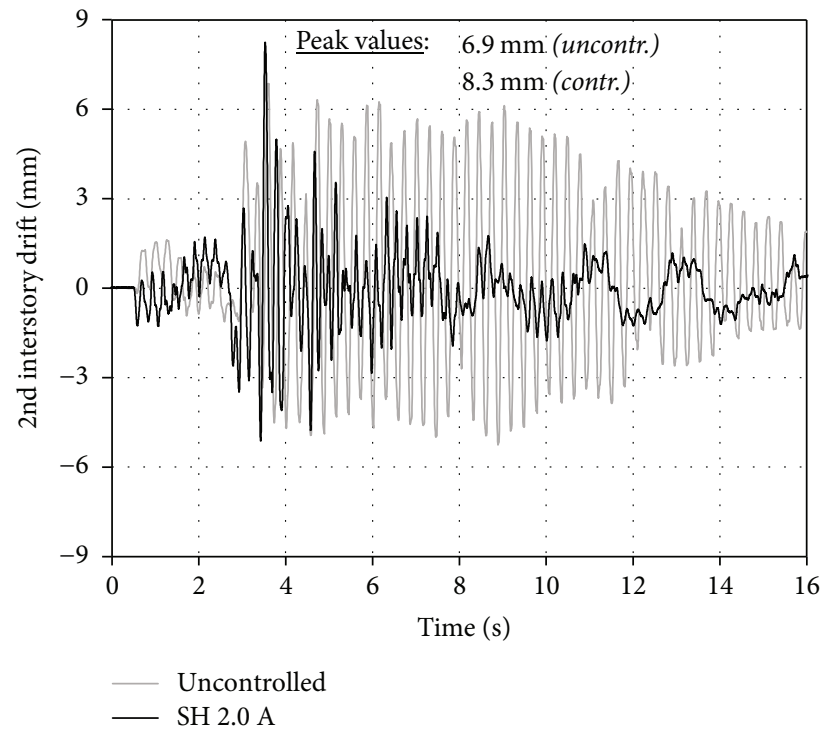

(d)

FIGURE 12: Response reduction in terms of interstory drifts for both SH1A and SH2A tests.

TABLE 2: Floor spectral accelerations for selected periods of vibration of nonstructural components, corresponding to the cases of (a) a component firmly fixed to the slab, (b) a partition wall, and an element in resonance with the first (c) and the second (d) frequencies.

\begin{tabular}{lccccccc}
\hline \multirow{2}{*}{ Case } & \multirow{2}{*}{$T[\mathrm{~s}]$} & \multicolumn{2}{c}{ Spectral 1st floor acceleration $[\mathrm{g}]$} & \multicolumn{3}{c}{ Spectral 2nd floor acceleration [g] } \\
& & Uncontrolled & SH 1 A & SH 2 A & Uncontrolled & SH 1 A & SH 2 A \\
\hline (a) & 0.00 & 0.67 & 0.45 & 0.97 & 1.11 & 0.54 & 0.91 \\
(b) & 0.02 & 0.72 & 0.71 & 1.63 & 1.21 & 0.80 & 1.29 \\
(c) & $0.24-0.29$ & 17.00 & 2.30 & 2.70 & 33.00 & 5.10 & 7.00 \\
(d) & $0.08-0.09$ & 4.70 & 4.10 & 5.00 & 3.60 & 2.40 & 2.80 \\
\hline
\end{tabular}

\section{Conclusions}

The main results of a wide experimental campaign on a near full-scale semiactively controlled steel building have been presented and discussed. A sky-hook damping based control algorithms driving SA MR dampers have been investigated through shaking table tests under the action of a natural earthquake. The control logic is able to change in real-time the dynamical properties of the dampers according to the actual values of response quantities measured in the close 


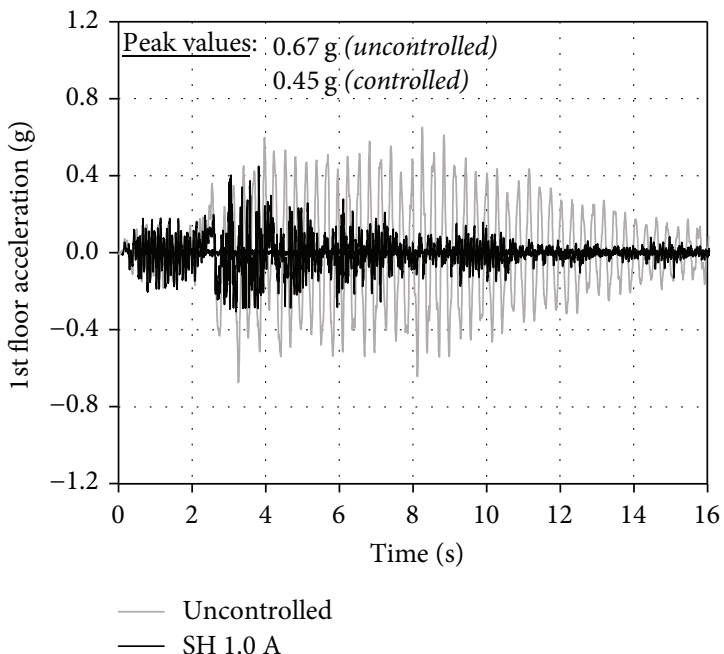

(a)

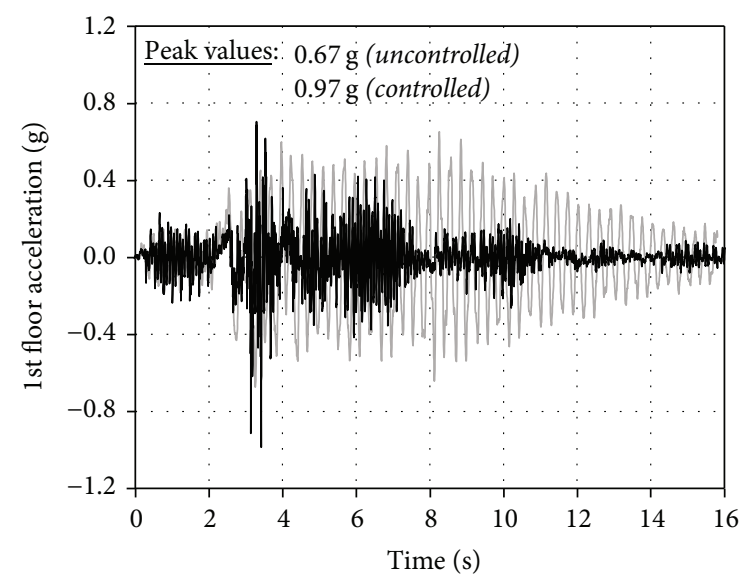

Uncontrolled

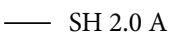

(c)

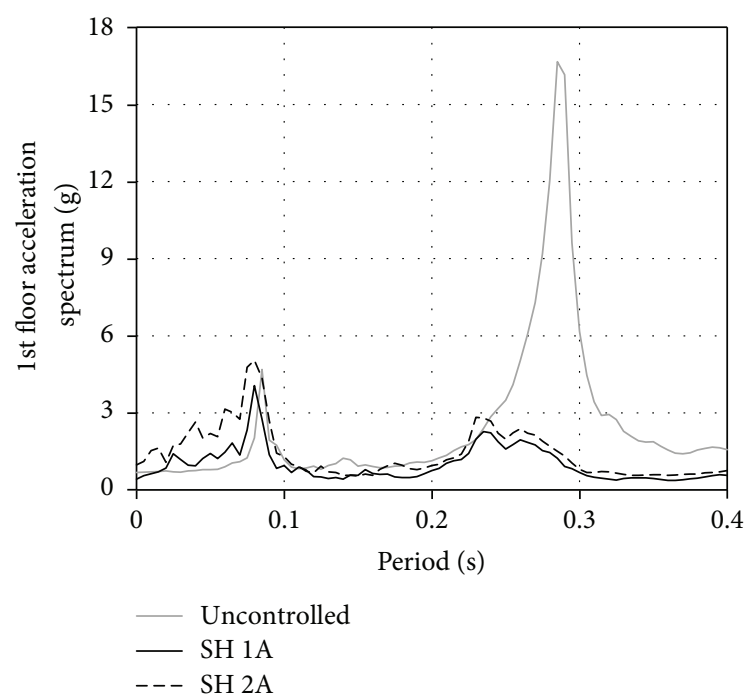

(e)

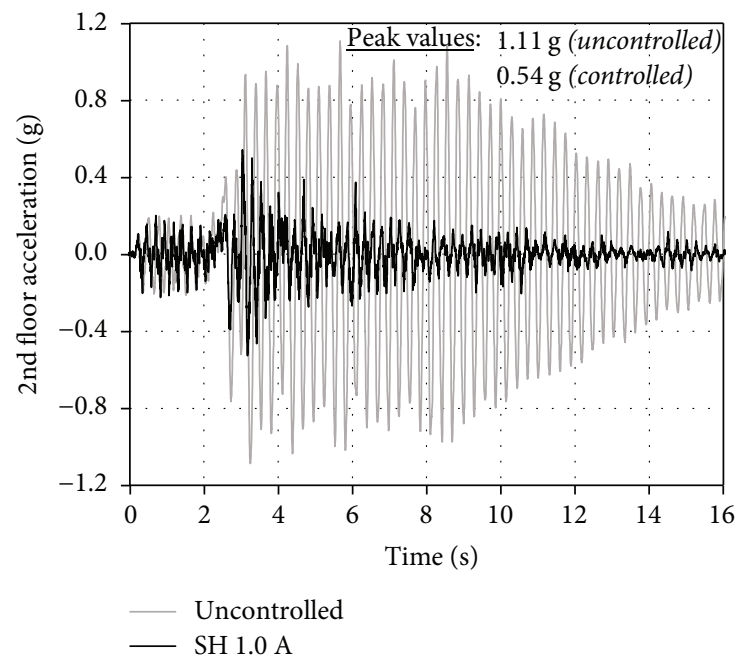

(b)

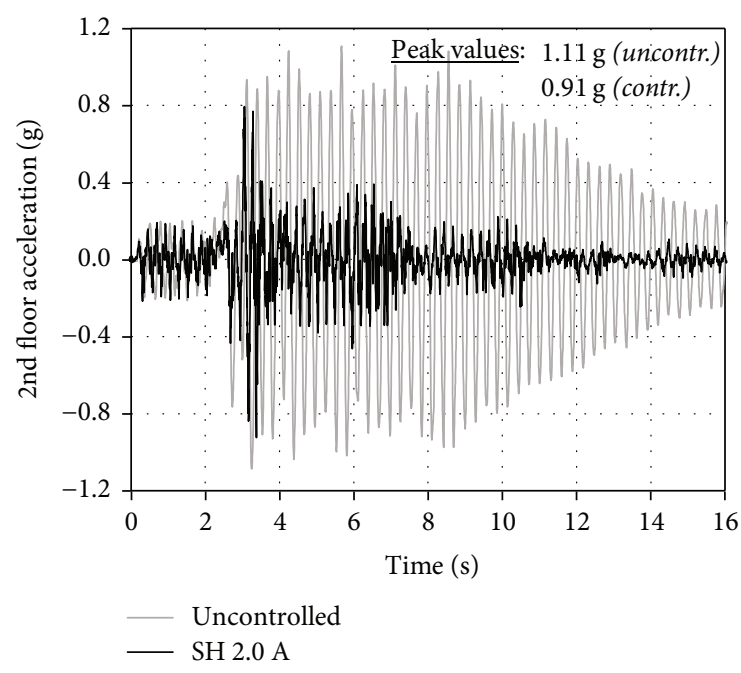

(d)

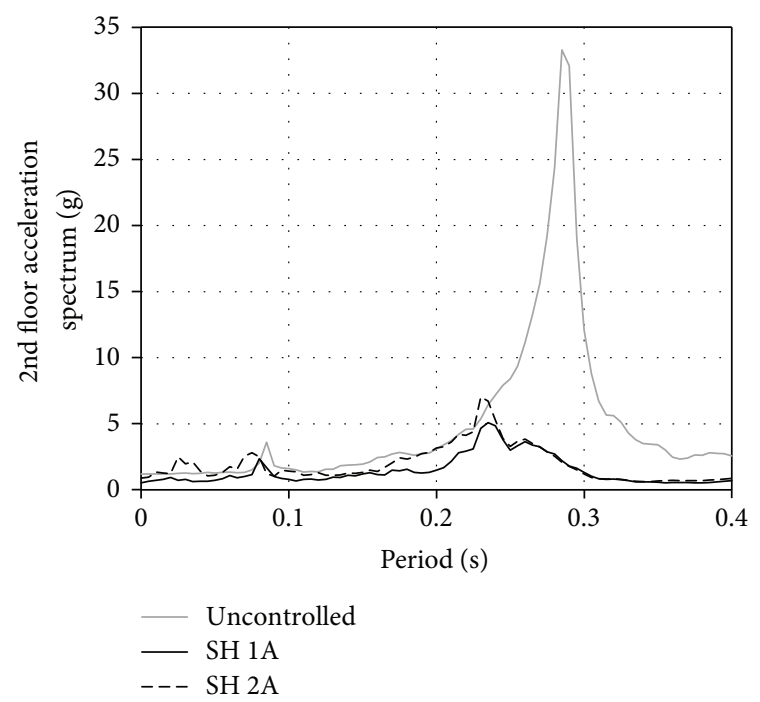

(f)

FIGURE 13: Comparison of uncontrolled and controlled (tests SH1A and SH2A) response in terms of floor acceleration time histories (a to d) and spectra $(e, f)$. 
surroundings of the dampers. It aims to make the MR device mimic the behaviour of a damper constrained to the fixed space.

The effectiveness of the control system related to two different configurations of the controller has been compared. The latter were different only because of the maximum value of feeding current ( $1 \mathrm{~A}$ and $2 \mathrm{~A}$, resp.). The gained results led to the following main conclusions.

The experimental response reduction in terms of interstory drifts and accelerations achieved by SA control system in the SH1A case, compared to the bare, uncontrolled frame, can be even close to $50 \%$. The control strategy results in being particularly effective in reducing the floor accelerations, so achieving a high seismic protection for nonstructural components and contents potentially installed at the two storeys of the structure. The performance of the SA controller configured with $i_{\max }=2 \mathrm{~A}$ (test $\mathrm{SH} 2 \mathrm{~A}$ ) is not satisfactory to the same extent. As a matter of fact, the structural response in this case is slightly better than the uncontrolled case, or even worse, in terms of displacement as well as acceleration demand.

The so different performance of the control strategy in the cases SH1A and SH2A is mainly due to the fact that the MR devices were installed at the first storey only. When they were set to be "stronger" (i.e., when higher intensity of current was used), reaction forces became higher and resulted in a more abrupt change over time. Since they acted at the first level only, they undesirably tended to activate the participation of the second vibration mode, which was less involved in the motion of the uncontrolled structure. This outcome could be taken as a general indication for semiactively controlled systems when smart devices cannot be present on all floors (e.g., for architectural or cost limitations). In similar cases, the additional damping should not be too high, so as not to favor irregularities in height and undesired amplification of the structural response.

Further analyses have been programmed by the authors to be done with reference to different seismic loads and configurations of the controller. This will allow gathering additional information useful to understand how, in real applications, the SA control strategy could be calibrated in order to be effective in reducing the structural response.

\section{Conflicts of Interest}

The authors declare that they have no conflicts of interest.

\section{Acknowledgments}

The research activity has been supported by the University of Naples "Parthenope" with a grant within the call "Support for Individual Research for the 2015-17 Period" issued by Rectoral Decree no. 953-954/2016 and in the framework of the ReLUIS Research Project funded by the Italian Department for Civil Protection. The above supports are gratefully acknowledged. The dampers have been designed, manufactured, and provided for free by Maurer Söhne (Munich, Germany) that is also acknowledged for the support.

\section{References}

[1] T. Kobori, M. Takahashi, T. Nasu, N. Niwa, and K. Ogasawara, "Seismic response controlled structure with active variable stiffness system," Earthquake Engineering \& Structural Dynamics, vol. 22, no. 11, pp. 925-941, 1993.

[2] M. J. Crosby and D. C. Karnopp, The Shock and Vibrations Bulletin, vol. 43, Naval Research Laboratory, Washington DC, USA, 1973.

[3] D. Cao, X. Song, and M. Ahmadian, "Editors' perspectives: road vehicle suspension design, dynamics, and control," Vehicle System Dynamics, vol. 49, no. 1-2, pp. 3-28, 2011.

[4] Z.-X. Li and L.-H. Xu, "Shaking-table test on semi-active control for seismic response of tall buildings using MRF-04K damper," in Proceedings of the 13th World Conference on Earthquake Engineering, Vancouver, B.C., Canada, 2004.

[5] H.-J. Lee, H.-J. Jung, S.-J. Moon, S.-K. Lee, E.-C. Park, and K.-W. Min, "Experimental investigation of MR damper-based semiactive control algorithms for full-scale five-story steel frame building," Journal of Intelligent Material Systems and Structures, vol. 21, no. 10, pp. 1025-1037, 2010.

[6] M. Basili, M. De Angelis, and G. Fraraccio, "Shaking table experimentation on adjacent structures controlled by passive and semi-active MR dampers," Journal of Sound and Vibration, vol. 332, no. 13, pp. 3113-3133, 2013.

[7] Y.-J. Cha, J. Zhang, A. K. Agrawal et al., "Comparative studies of semiactive control strategies for MR dampers: Pure simulation and real-time hybrid tests," Journal of Structural Engineering (United States), vol. 139, no. 7, pp. 1237-1248, 2013.

[8] N. Caterino, M. Spizzuoco, and A. Occhiuzzi, "Shaking table testing of a steel frame structure equipped with semi-active MR dampers: comparison of control algorithms," Smart Structures and Systems, vol. 15, no. 4, pp. 963-995, 2015.

[9] F. C. Ponzo, A. Di Cesare, C. Moroni et al., "JET-PACS: Joint Experimental Testing on Passive and semiActive Control Systems," in Proceedings of the L'Ingegneria Sismica in Italia - XIII Convegno Nazionale dell'ANIDIS, Bologna, Italy, 2009.

[10] A. Occhluzzi and M. Spizzuoco, "Experimental analysis of a semi-actively controlled steel building," Structural Engineering and Mechanics, vol. 19, no. 6, pp. 721-747, 2005.

[11] J. A. Inaudi, "Performance of variable-damping systems: theoretical analysis and simulation," in Structural Control for Civil and Infrastructure Engineering, F. Casciati and and G. Magonette, Eds., World Scientific, pp. 301-316, 2000.

[12] C. W. Stammers and T. Sireteanu, "Vibration control of machines by use of semi-active dry friction damping," Journal of Sound and Vibration, vol. 209, no. 4, pp. 671-684, 1998.

[13] N. Caterino, M. Spizzuoco, and A. Occhiuzzi, "Understanding and modelling the physical behaviour of magnetorheological dampers for seismic structural control," Smart Materials and Structures, vol. 20, no. 6, Article ID 065013, 2011.

[14] D. Karnopp, M. J. Crosby, and R. A. Harwood, "Vibration control using semi-active force generators," Journal of Manufacturing Science and Engineering, vol. 96, no. 2, pp. 619-626, 1974.

[15] N. Caterino, M. Spizzuoco, and A. Occhiuzzi, "Promptness and dissipative capacity of MR dampers: experimental investigations," Structural Control and Health Monitoring, vol. 20, no. 12, pp. 1424-1440, 2013.

[16] A. Di Cesare, F. C. Ponzo, D. Nigro, M. Dolce, and C. Moroni, "Experimental and numerical behaviour of hysteretic and visco-recentring energy dissipating bracing systems," Bulletin of Earthquake Engineering, vol. 10, no. 5, pp. 1585-1607, 2012. 
[17] N. Caterino, M. Spizzuoco, J. M. Londoño, and A. Occhiuzzi, "Experimental issues in testing a semiactive technique to control earthquake induced vibration," Modelling and Simulation in Engineering, vol. 2014, Article ID 535434, 11 pages, 2014.

[18] A. Preumont, Vibration control of active structures, Kluwer Academic Publishers, 2nd edition, 2002.

[19] N. Caterino, M. Spizzuoco, and A. Occhiuzzi, "Skyhook-based monitoring and control of a steel building under seismic action," in Proceedings of the 2016 IEEE Workshop on Environmental, Energy, and Structural Monitoring Systems, EESMS 2016, Italy, June 2016.

[20] J. L. Sackman and J. M. Kelly, "Seismic analysis of internal equipment and components in structures," Engineering Structures, vol. 1, no. 4, pp. 179-190, 1979.

[21] NTC08, "Norme Tecniche per le Costruzion," D.M. 14.01.2008. (In Italian). 


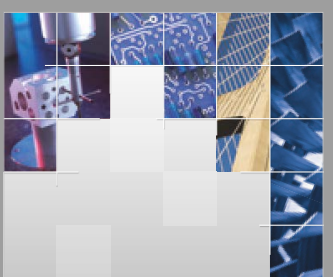

\section{Enfincering}
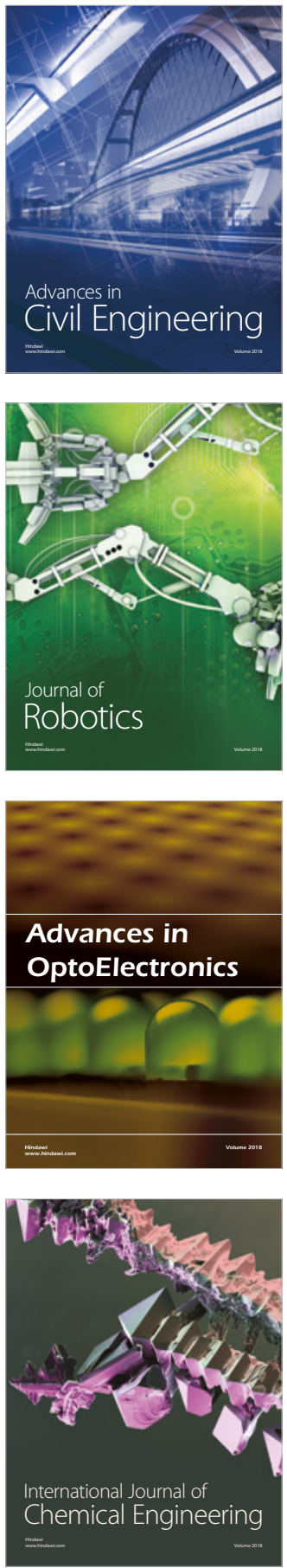

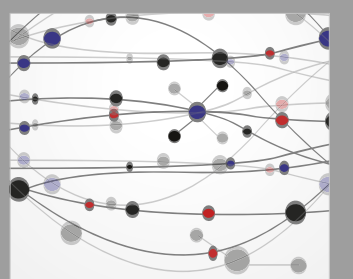

\section{Rotating \\ Machinery}

The Scientific World Journal

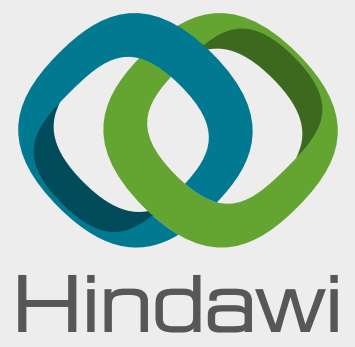

Submit your manuscripts at

www.hindawi.com
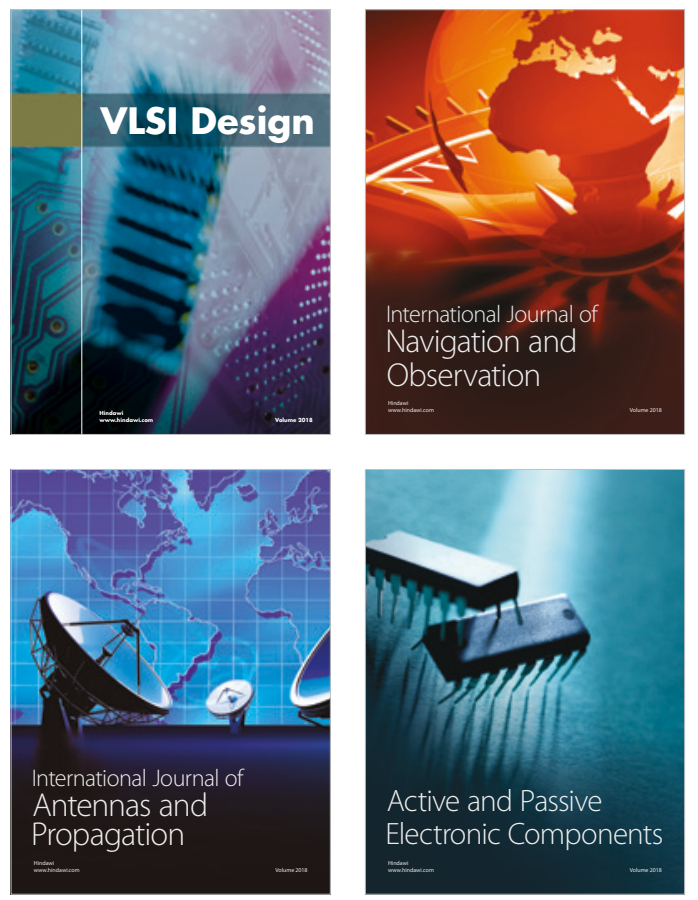
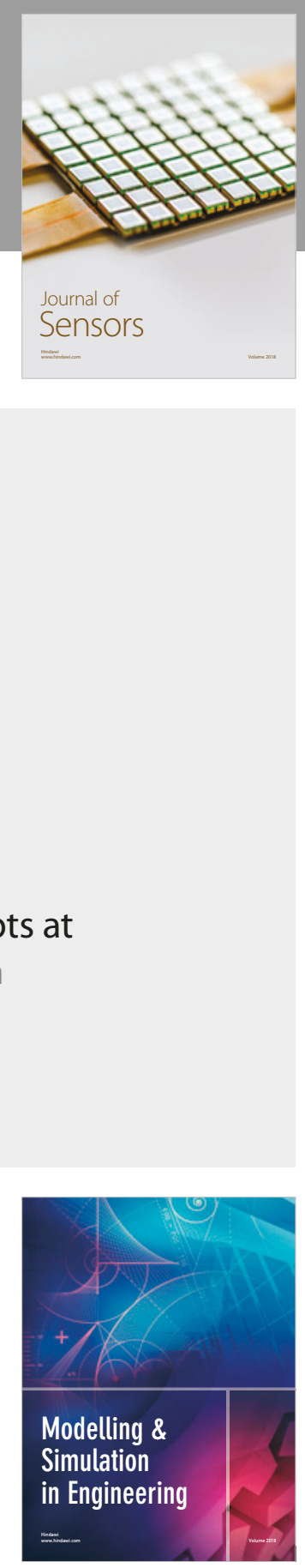

\section{Advances \\ Multimedia}
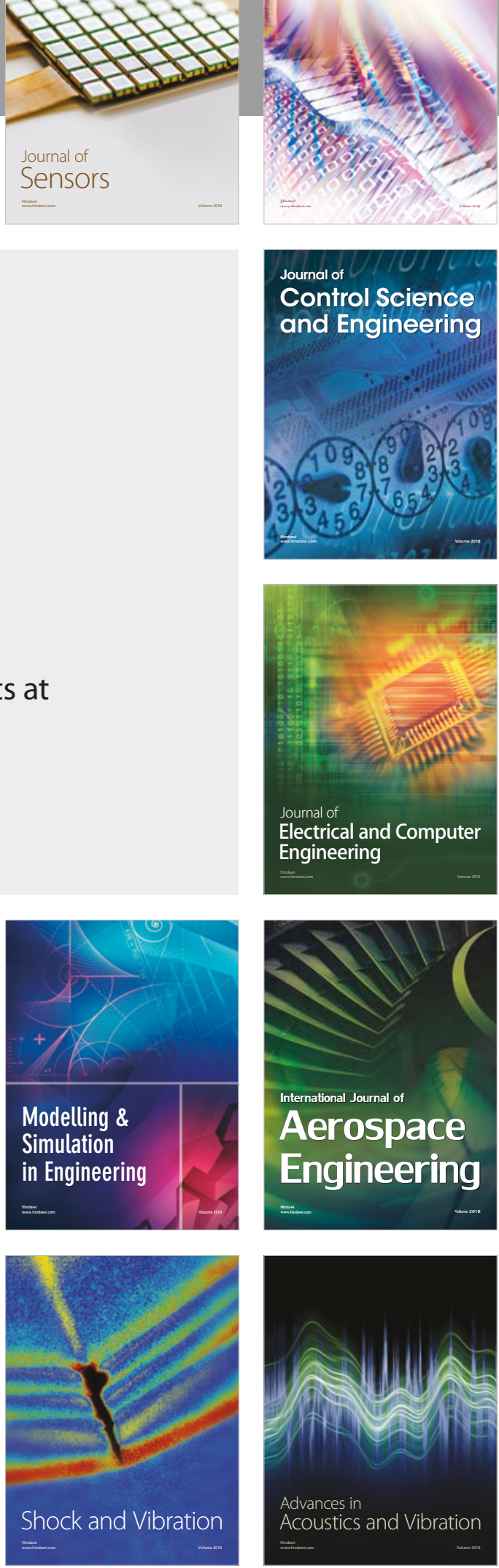